\section{Quantum theory: certainty in uncertainty}

\author{
P. W. Atkins
}

The Cosmic Code: Quantum Physics as the Language of Nature. By Heinz R. Pagels. Pp.370. ISBN 0-671-24802-2. (Simon \& Schuster:1982.) $\$ 17.50$.

THIS is a book aimed squarely at the general reader with the intention of conveying not only the excitement of modern science but also the revolution in our comprehension of the world that accompanied the introduction of quantum theory. There are three parts: an account of quantum theory; a description of modern particle physics; and a brief personal reflection on the nature of physical laws. The material is presented nonmathematically and will be accessible to anyone who is interested in what the author rightly regards as the nonpareil of this century's social and cultural events. The text itself is characterized by the author's almost boyish eagerness to communicate his enthusiasm, and is sometimes so anxious to please that it trips over its own naivety ("Most physicists enjoy the outdoors") to the point, in one place, of ascribing the well-known allegory of Paley's watch to a speaker at a recent conference.

The most important section is the first, which occupies about half the book. It is woven around the biography of Einstein and his transition from being a revolutionary innovator to one who lost "his hot-line to the Old One" and refused to accept that determinism was dead. The intention of the section, apart from emphasizing a moral, is to present an exposition of quantum weirdness; the loss of objectivity, its replacement by an observer-created reality and the rejection of determinism - "the quantum theory is a theory of an instrumentally detected material reality"' (p.99). Underlying (if not stemming from) this intention is an opposition to material reductionism (a programme that "cannot be carried out", p.135). The basis of this view is an acceptance of the Copenhagen interpretation of quantum mechanics with its emphasis on the meaninglessness of a concept until its mode of measurement has been defined. Pagels adopts the party line on this issue, and as such does a very good job. His argument leads, convincingly, to the ultimate quantum weirdness that "human intention influences the structure of the world"' (p. 95), and the view that "quantum reality" is statistical.

Convincingly, that is, until one stops to think. In my view, for what it is worth, determinism entered physics with the uncertainty principle, and the principal confusion pervading so much interpretative commentary on quantum mechanics (and finding such lucid expression in this book) is the failure to distinguish between measurement and specification. I should explain what I mean. With quantum theory we first encountered a constraint on our description of the world. Classical mechanics attempted unknowingly to be overcomplete in its specification; quantum mechanics is the first theory we have (and possibly the last we shall need) that respects nature by refraining from imposing a description too strong for it to support. Quantum mechanics is fully deterministic in the sense that the evolution of a state under the influence of a hamiltonian is perfectly well-defined; it ceases being deterministic only when we insist upon reverting to an overcomplete discussion by asking questions that classical mechanics has conditioned us to believe are answerable or when, after we have prepared a system in an eigenstate of one observable, we seek to predict the outcome of another observation that classical mechanics has conditioned us to expect but which quantum mechanics proscribes. No wonder our predictions then squirt out in all directions! Quantum "randomness" is nothing more than this reaction to false expectation. Likewise, the strict Copenhagen requirement of "meaningless until measured" is a confusion between a mode of interpretation and a manner of exhibiting self-consistency (or at least of constructing thought experiments to show that there is no inconsistency). This viewpoint is consistent with Einstein's whose views, I suspect, have been overborne by the appeal of an interpretation that hangs on to classical modes of thought. This emphasizes yet again the delicacy of the balance in the dictum (p.67) that "physicists are conservative revolutionaries pseudoscientists lack that commitment to existing principles".

My position then is strict determinism (or better, neodeterminism, because it must not be confused with classical determinism) showing itself as indeterminism only when false, culturally conditioned, classical questions are asked. Hence, in my view, Pagels has focused on a wholly misleading and fallacious interpretation which cannot fail to imbue his readers with a false impression of the nature of "quantum reality". I have to admit, though, that he has the forces of neoconvention ranged on his side (which does not mean he is right), and readers of this engaging book will leave it with a clear grasp of a conventional and widely accepted interpretation.

I have concentrated on a single aspect of the book, but one that lies at its core. There are many other remarks with which the careful reader will probably disagree. For instance, I could criticize at equal length the remarks to the effect that differences between macroscopic and microscopic phenomena are qualitative and not merely quantitative (p.128), that historical events are not reducible to individual acts on the part of human beings (p.131), and that quantum reality is statistical and therefore outside mathematics (p.337). There is also a peculiar blindness to the technical meaning of a "selfish" gene but not to its analogue "charm". There is also much to admire, especially the author's manifest deep concern to communicate.

P. W. Atkins is a Fellow of Lincoln College, Oxford, and author of The Creation $(W . H$. Freeman, 1981).

\section{Getting JET off the ground}

\author{
John B. Adams
}

A European Experiment: The Launching of the JET Project. By Denis Willson. Pp.181. Hbk ISBN 0-85274-543-5; pbk ISBN 0-85274-549-4. (Adam Hilger/ Heyden: 1981.) Hbk £10.50, \$23; pbk £6.95, $\$ 15.50$.

EVERYBODY who is concerned in Western European affairs should be interested in this account of "a European experiment". Opponents of the European Community system will find in it ample confirmation of their criticisms; supporters will see in it a triumph of the European spirit over national self-interest. For those who are convinced that international action is now the only way of carrying out major scientific enterprises in Europe, it will come as a sobering reminder of how very difficult it is to reach agreement at the European level.

The subject of the book is the launching of the Joint European Torus (JET) project, the latest and largest experiment in the world-wide effort which started back in the 1950 s to exploit nuclear fusion reactions as a useful energy source. To make this dramatic story (or lamentable comedy as it was once described) intelligible to the layperson, the author has first to explain something about plasma physics, the general history of nuclear fusion research and the complexities of the European Community system, all of which he does with commendable clarity. Having provided the reader with the essential background information, he then describes the specific problems presented by JET.

The principal difficulty that arose in the launching process and the reason for the two-year delay in the approval of the project was the problem of where to locate it. After the failure of the Community to agree to a common nuclear fission reactor programme and the consequent disarray this caused to the Euratom laboratory at ISPRA, which was set up to carry out that programme, the Commission devised a 